\title{
Effect of diet on the measurement of liver elasticity by real-time shear wave elastography in normal subjects
}

\author{
Jin $\mathrm{DING}^{1}$, Li LI ${ }^{1}$, Hong-Yuan XUE ${ }^{1 *}$
}

\begin{abstract}
To evaluate the liver stiffness measurement (LSM) of normal people before and after diet using real-time shear wave elastography (SWE), and to explore the effect of diet on liver elasticity. Fifty-four healthy volunteers were selected and $480 \mathrm{~mL}$ of a standard diet containing $391 \mathrm{kcal}$ were administrated. The LSM before diet and at 30 minutes after diet was significantly higher than baseline LSM. The LSM at 60 minutes after diet was significantly higher than that before diet. The LSM at 120 minutes after diet was significantly less than that before diet. $75 \%$ of the volunteers reached the peak of liver stiffness at 30 minutes or 60 minutes after diet. The LSM increased by more than $20 \%$ in $31 \%$ subjects, increased by less than $20 \%$ in $48 \%$, and remained or decreased in $21 \%$. The blood flow volume of portal vein was $692.02 \pm 130.69 \mathrm{~mL} / \mathrm{min}$ before diet, and it reached the maximum value of $776.41 \pm 151.45 \mathrm{~mL} / \mathrm{min}$ at $30 \mathrm{~min}$ after diet. Diet could affect the Young's modulus measurement of liver. In order to avoid the effect, it is suggested to use real-time shear wave elastic imaging to measure the Young's modulus of liver on an empty stomach.
\end{abstract}

Keywords: liver stiffness measurement; real-time shear wave elastography; diet; Young's modulus.

Practical Application: The effect of diet on LSM using real-time SWE, and on liver elasticity.

\section{Introduction}

Chronic liver disease is a substantial world-wide problem. Its major consequence is increasing deposition of fibrous tissue within the liver leading to the development of cirrhosis with its consequences of portal hypertension, hepatic insufficiency, and hepatocellular carcinoma (Barr, 2018). The stage of liver fibrosis is important to determine prognosis, surveillance, prioritize for treatment, and potential for reversibility. The process of fibrosis is dynamic and regression of fibrosis is possible with treatment of the underlying conditions (Barr, 2018). Previously, the only method of staging the degree of fibrosis was liver biopsy. However, the application of liver biopsy is limited due to its invasive procedure, which is inherent risk to the subjects.

Transient elastography (TE) is a nonimaging elastographic technique, which is commonly used to measure liver elasticity, noninvasive and rapid assessment of liver fibrosis (Castera, 2012; Lemoine et al., 2014). The novel type of real-time shear wave elastography (SWE) technology emits shear waves to tissues, and captures the propagation information in tissues. The Young's modulus $(\mathrm{kPa})$ is used to represent the stiffness of tissues. It is not only a real-time processing, full-scale display, quantitative evaluation of tissue elastic imaging mode, while this method could also overcome the impact of potential human factors such as pressure frequency and pressure size, with good repeatability of operation. The evidence suggests that SWE is more accurate than TE (Barr, 2018).

Liver stiffness measurement (LSM) could be affected by exercise, diet, inflammation, fatty liver disease, cholestasis and other pathological factors (Xu et al., 2020; Darweesh et al.,
2020). The impact of diet on LSM has been used to evaluated using TE technology (Berzigotti et al., 2013; Popescu et al., 2013). However, the influence of diet on SWE has been seldom evaluated. Therefore, this study was aimed to evaluate the effect of diet on LSM using real-time SWE, and to explore the effect of diet on liver elasticity.

\section{Methods}

This study is approved by the Ethics Committee of Hebei General Hospital. Written informed consent was obtained.

\subsection{Subjects}

Fifty-four healthy volunteers were selected from January 2019 to October 2019 in Hebei Provincial People's hospital. Two volunteers were excluded from the study due to fatty liver observed by two-dimensional ultrasound examination, and a total of 52 volunteers were included in the study.

Inclusion criteria were the healthy volunteers without history of liver disease. All the volunteers participated in the experiment voluntarily and signed informed consent. The exclusion criteria were following, 1) abnormal hepatitis markers and liver function examination; 2) Ascites, liver lesions (such as liver abscess, hemangioma, nodular liver cancer, etc.), diffuse liver lesions (such as liver schistosomiasis, liver cirrhosis and other diffuse liver diseases);3) Heart failure or abnormal increase of inferior vena cava $(9-38 \mathrm{~mm}$ ) and/or hepatic vein diameter (5-10 mm); 4) gestation; 5) Taking beta blockers or vasoactive 
drugs; 6) unable to complete breathing training and breath holding; 7) food intake in the last 8 hours.

\subsection{Examination}

SuperSonic Imagine Aixplorer color Doppler ultrasound diagnostic instrument was used, the probe with the frequency of 3-5 MHz was selected. The volunteers took the supine position, kept calm breathing, fully exposed the right upper abdomen. Couplant was coated the probe and vertically pressed against the skin of the patient. Routine ultrasound examination was used to exclude liver lesions and diffuse lesions. The diameter of the main portal vein and the portal vein $1-2 \mathrm{~cm}$ away from the left and right branches of the portal vein were measured.

Spectral Doppler mode was selected, sampling volume was placed in the center of the portal vein lumen, so that the angle between the emitted ultrasound beam and the long axis of the blood vessel was less than $60^{\circ}$, the blood flow velocity of the portal vein was measured. Adjust to elasticity-imaging mode, the probe was placed in the 4 th or 5 th intercostal space of the right middle clavicle of the volunteer, the region of interest (ROI) was placed in the right lobe of the liver, with the detection depth of $3-4 \mathrm{~cm}$. During the measurement, the subjects were instructed to hold their breath, avoid the large vascular structure, and stand for 3-4 s, after the image is stable, the image was recorded. All measurements were performed by a single researcher with 5 years experiences in ultrasonography and liver elastography.

The quantitative analysis system (Q-box) was used and the diameter of Q-box was adjusted to $15 \mathrm{~mm}$. The instrument would automatically calculate and show the Young's modulus (unit: $\mathrm{kPa}$ ) of liver tissue in the region of interest, including maximum value (Emax), average value (Emean), minimum value (Emin) and standard deviation (SD).

\subsection{Study protocol}

Fifty-two volunteers were given $480 \mathrm{~mL}$ standard diet of $391 \mathrm{kcal}$ (containing $24.385 \mathrm{~g}$ carbohydrate, $23.21 \mathrm{~g}$ fat and $20.69 \mathrm{~g}$ protein). The Young's modulus of liver was measured before diet and $30 \mathrm{~min}, 60 \mathrm{~min}, 90 \mathrm{~min}$ and $120 \mathrm{~min}$ after diet. The liver Young's modulus Emean was repeated measured for three times. The average values of the three measurements were statistically analyzed, and the age, gender, height and weight of the volunteers were recorded.

\subsection{Assessment}

Baseline value of liver stiffness: LSM before diet;

The change of liver stiffness $=$ LSM at $60 \mathrm{~min}$ after diet LSM before diet;

The peak value of liver stiffness: the maximum value of LSM after diet;

The percentage of increase in liver stiffness after diet $=$ (The peak value of liver stiffness - Baseline value of liver stiffness)/ Baseline value of liver stiffness;
The baseline value of portal vein blood flow: the portal vein blood flow before diet;

The change of portal vein blood flow $=$ portal vein blood flow at 60 minutes after diet - portal vein blood flow before diet.

Portal vein blood flow $(\mathrm{mL} / \mathrm{min})=$ portal vein diameter $(\mathrm{cm})^{2} /$
$4 \times \pi \times 60 \times$ portal vein velocity $(\mathrm{cm} / \mathrm{s})$

Body mass index $(\mathrm{BMI})=\operatorname{weight}(\mathrm{kg}) /$ height $^{2}(\mathrm{~m})$

\subsection{Statistical analysis}

SPSS 21.0 software was used to analyze the original data, the liver Young's modulus and portal vein blood flow at each measurement point before and after diet were compared using repeated measurement multivariable analysis of variance (MANOVA) test. The data were further analyzed by paired sample $t$ test. The measurement data were expressed by $\bar{X} \pm \mathrm{S}$. Independent sample t test or Pearson correlation test were used to analyze the influence of age, gender, BMI, baseline value of portal vein blood flow, baseline value of liver stiffness, and portal vein blood flow on baseline LSM and LSM change after diet. The independent relationship between these parameters and baseline LSM and LSM changes after diet was evaluated by multiple linear regression model.

\section{Results}

\subsection{Baseline characteristics}

A total of 52 volunteers were enrolled in this study, with an average age of $25.98 \pm 1.38$ years. Male accounted for $33 \%(17 / 52)$, average BMI was $23.09 \pm 0.94 \mathrm{~kg} / \mathrm{m}^{2}$, while female accounted for $67 \%$ (35/52), average BMI was $19.80 \pm 1.70 \mathrm{~kg} / \mathrm{m}^{2}$ (Table 1 ).

\subsection{Values of LSM at different time points}

The average liver Young's modulus values of the whole sample and different gender volunteers after diet were different from those before diet (Figures 1 and 2) (Table 2).

The average LSM was $4.66 \pm 0.65 \mathrm{kpa}$ before diet and $4.92 \pm 0.69 \mathrm{kPa}$ at $30 \mathrm{~min}$ after diet, which was significantly higher than baseline LSM $(P<0.05)$. The LSM was $5.02 \pm 0.92 \mathrm{kPa}$ at 60 min after diet, which was also significantly higher than that before diet $(P<0.05)$. It was $4.54 \pm 0.68 \mathrm{kpa}$ at $90 \mathrm{~min}$ after diet, which was not significantly different compared with that before $\operatorname{diet}(P>0.05)$. At $120 \mathrm{~min}$ after diet, $\mathrm{LSM}$ was $4.21 \pm 0.58 \mathrm{kPa}$,

Table 1. Basic characteristics.

\begin{tabular}{lc}
\hline \multicolumn{1}{c}{ Index } & Value \\
\hline Age (years) & $25.98 \pm 1.38$ \\
Gender & \\
male & $17(33 \%)$ \\
female & $35(67 \%)$ \\
BMI $\left(\mathrm{kg} / \mathrm{m}^{2}\right)$ & \\
male & $23.09 \pm 0.94$ \\
female & $19.80 \pm 1.70$ \\
\hline
\end{tabular}




\section{A}
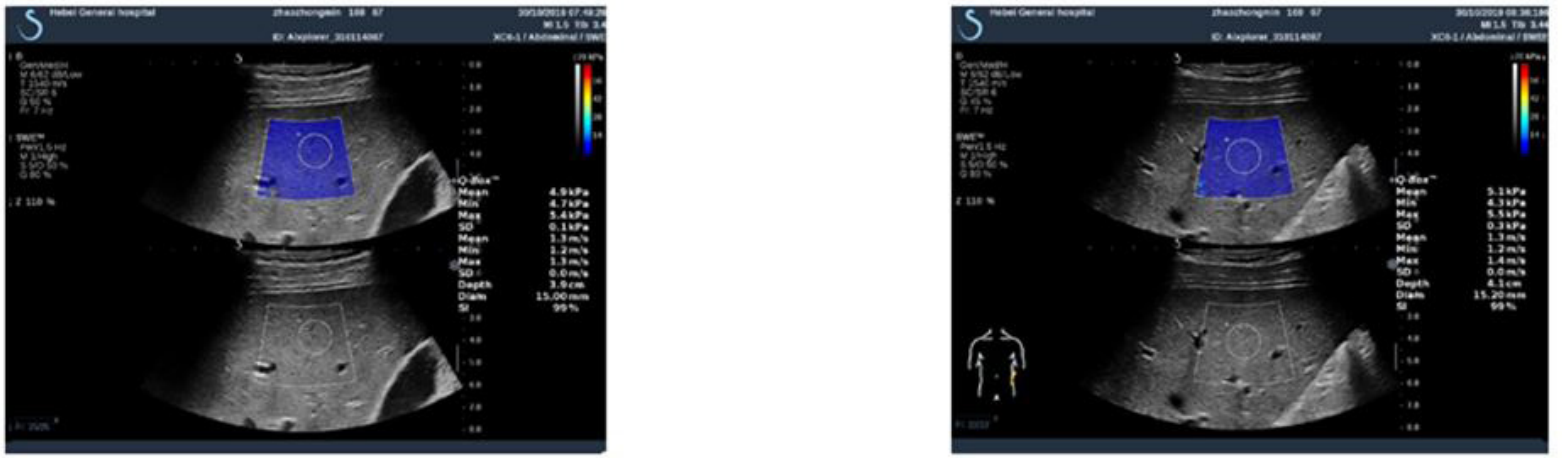

C
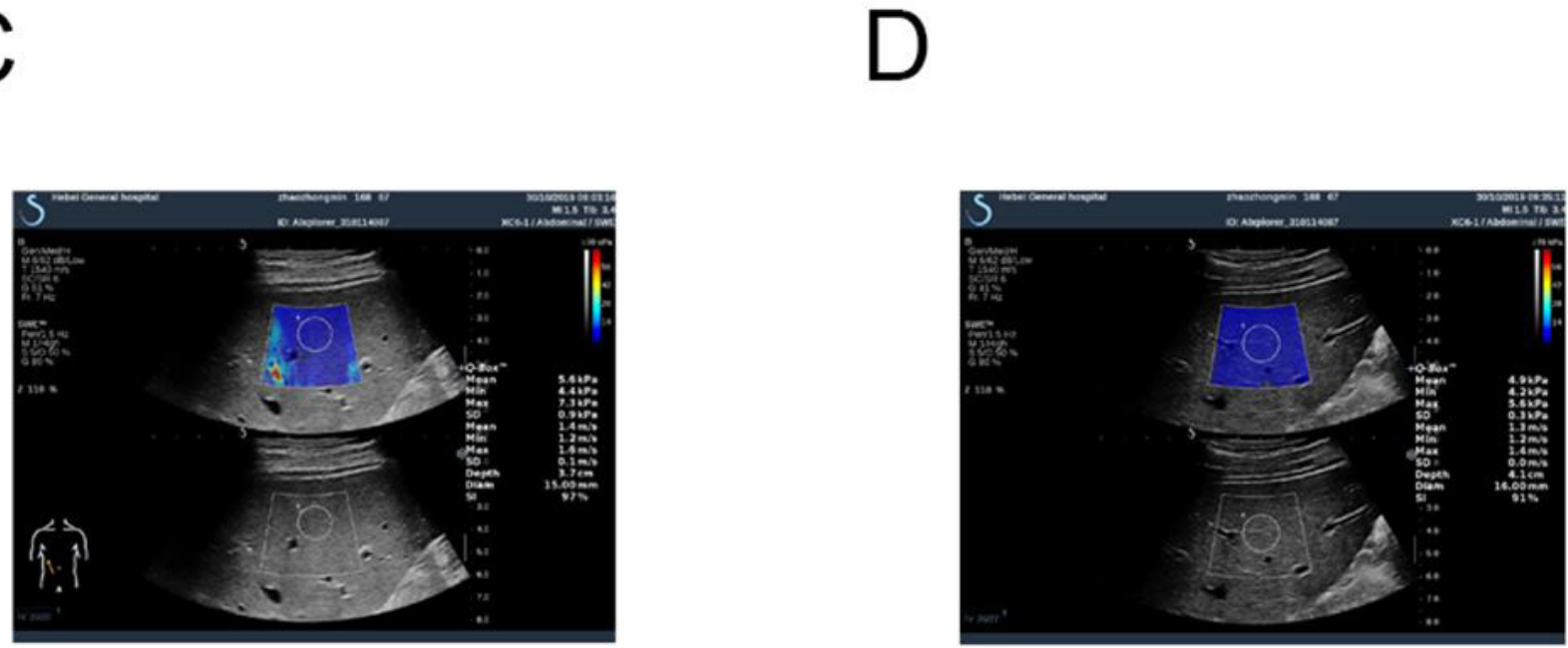

Figure 1. The SWE image of a male volunteer's right liver at different time points. (A) Before the diet Emean $=4.9 \mathrm{kpa}$; (B) 30 minutes after diet Emean $=5.1 \mathrm{kpa}$; (C) 60 minutes after diet Emean = 5.6 kpa; (D) 90 minutes after diet Emean $=4.9 \mathrm{kpa}$.

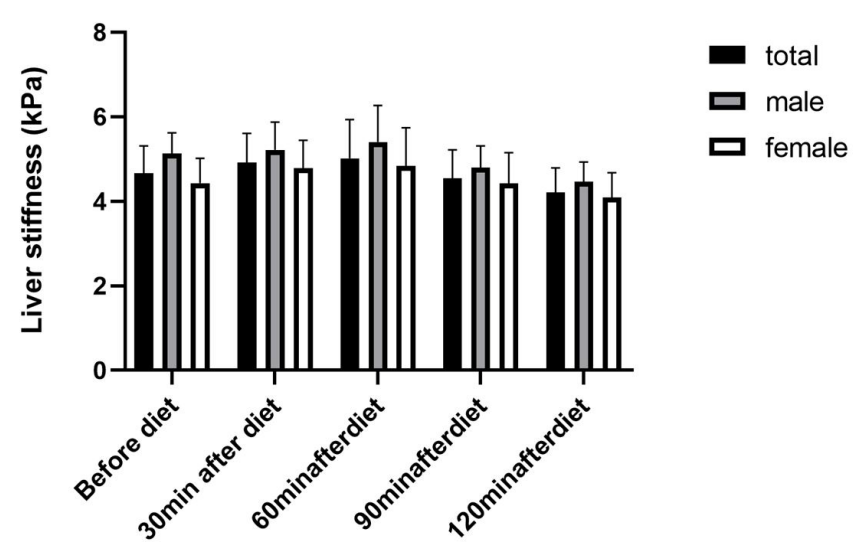

Time points

Figure 2. LSM values of all subjects and different genders at each measurement time point.
Table 2. Paired t-test of LSM at different measurement points.

\begin{tabular}{lcc}
\hline \multicolumn{1}{c}{ Group } & t & $\boldsymbol{P}$ \\
\hline Before diet vs. 30 min after diet & -3.821 & $<0.001^{*}$ \\
Before diet vs. 60 min after diet & -4.151 & $<0.001^{*}$ \\
Before diet vs. 90 min after diet & 1.611 & 0.113 \\
Before diet vs. 120 min after diet & 6.414 & $<0.001^{*}$ \\
30 min after diet vs. 60 min after diet & -1.297 & 0.200 \\
60 min after diet vs. 90 min after diet & 7.209 & $<0.001$ \\
90 min after diet vs. 120 min after diet & 8.162 & $<0.001$ \\
\hline
\end{tabular}

$P$ value is probability, which reflects the possibility of an event. $t$ is just a statistic of $\mathrm{t}$ test, from which $\mathrm{p}$ value is calculated. ${ }^{*} P<0.05$ was considered as significant difference.

which was significantly lower than that before $\operatorname{diet}(P<0.05)$. The average LSM of men before and after diets was significantly higher than that of women $(P<0.05)$.

There were significant differences in portal vein blood flow at different time points $(P<0.05)$. There were also significant 
differences in liver stiffness at different measuring points $(P<0.05)$. The changes of liver stiffness after diet were not related to gender and BMI, but there were significant differences in the mean LSM of different genders at each measurement time point $(P<0.05)$. Pearson correlation analysis showed that age $(\mathrm{r}=0.17, \mathrm{P}=0.21)$ and BMI $(\mathrm{r}=0.24, \mathrm{P}=0.08)$ were weakly positively correlated with LSM baseline $(P<0.05)$.

The paired t-test of average LSM showed that the liver stiffness at $30 \mathrm{~min}$ and $60 \mathrm{~min}$ after diet were significantly increased compared with the baseline value (Figure 2), which reached maximum value at $60 \mathrm{~min}$ (Figure 2). There was no significant difference between baseline value and LSM at $90 \mathrm{~min}$ after diet $(P>0.05)$, and liver stiffness at $120 \mathrm{~min}$ was significantly lower than that before diet $(P<0.05)$. The portal venous blood flow was $692.02 \pm 130.69 \mathrm{~mL} / \mathrm{min}$ before diet, while it increased by $84.39 \mathrm{~mL} / \mathrm{min}$ within $30 \mathrm{~min}$ after diet, and reached the maximum value of $776.41 \pm 151.45 \mathrm{~mL} / \mathrm{min}$ at $30 \mathrm{~min}$, then decreased continuously (Table 3 ).

\subsection{Proportion of LSM peak and percentage increase in LSM after diet}

The proportion of patients with liver stiffness reaching the peak at different measurement points after diet was shown in Table $4.33 \%$ (17/52) of the volunteers reached the peak value of liver stiffness at $30 \mathrm{~min}$ after diet, $42 \%$ (22/52) of the volunteers reached the peak at $60 \mathrm{~min}$ after diet, $4 \%(2 / 52)$ of the volunteers had the highest value of Young's modulus at $90 \mathrm{~min}$ after diet. A total of 79\% (41/52) of the volunteers showed an increase in LSM after diet, while $21 \%(11 / 52)$ of the volunteers had no change or decrease in the liver stiffness. $48 \%$ (25/52) of the volunteers had an increase of liver stiffness of less than $20 \%$, while $31 \%$ (16/52) had an increase of more than $20 \%$.

\subsection{Peak value of liver stiffness}

The average peak value of liver stiffness of the whole population and different gender volunteers was $5.12 \pm 0.76 \mathrm{kPa}$ in female, which increased by $15.6 \%$ compared with baseline, and that of male was $5.56 \pm 0.78 \mathrm{kpa}$, which increased by $8.3 \%$ higher than that of baseline. The increase rate of women was larger than that of men.

\subsection{Multiple linear regression analysis of LSM baseline and LSM change}

Multiple linear regression analysis showed that age, BMI and LSM baseline had no significant correlation, and BMI $(r=-0.002)$, age $(r=0.016)$ had no correlation with LSM changes (Table 5). There was no correlation between the baseline value of portal vein blood flow and the baseline value of liver stiffness, the change of portal vein blood flow and liver stiffness, or the baseline value of liver stiffness and the change of liver stiffness.

\section{Discussion}

Multiple studies have shown that liver stiffness has a good correlation with the degree of liver fibrosis (Kjærgaard et al., 2017; Mulabecirovic et al., 2018). However, there are still some
Table 3. Paired t-test of portal vein blood flow at different measuring points.

\begin{tabular}{|c|c|c|c|}
\hline Group & $\begin{array}{c}\text { Portal vein blood } \\
\text { flow }\end{array}$ & $\mathbf{t}$ & $P$ \\
\hline Before diet & $692.02 \pm 130.69$ & & \\
\hline vs. $30 \mathrm{~min}$ after diet & $776.41 \pm 151.45$ & -9.500 & $<0.05^{\star}$ \\
\hline $60 \mathrm{~min}$ after diet & $684.11 \pm 121.16$ & 2.235 & $<0.05^{*}$ \\
\hline 90 min after diet & $666.23 \pm 96.88$ & 2.421 & $<0.05^{\star}$ \\
\hline $120 \mathrm{~min}$ after diet & $624.26 \pm 93.13$ & 4.980 & $<0.05^{*}$ \\
\hline $\begin{array}{l}30 \text { min after diet vs. } 60 \mathrm{~min} \\
\text { after diet }\end{array}$ & & 11.076 & $<0.05^{*}$ \\
\hline $\begin{array}{l}60 \text { min after diet vs. } 90 \mathrm{~min} \\
\text { after diet }\end{array}$ & & 1.908 & $>0.05^{\star}$ \\
\hline $\begin{array}{l}90 \text { min after diet vs. } 120 \mathrm{~min} \\
\text { after diet }\end{array}$ & - & 6.476 & $<0.05^{*}$ \\
\hline
\end{tabular}

Table 4. Proportion of LSM peak at different measuring points after diet.

\begin{tabular}{lcc}
\hline \multicolumn{1}{c}{ Time after diet } & Proportion & Total \\
\hline $30 \mathrm{~min}$ & $33 \%(17)$ & $79 \%(41)$ \\
$60 \mathrm{~min}$ & $42 \%(22)$ & \\
$90 \mathrm{~min}$ & $4 \%(2)$ & \\
$120 \mathrm{~min}$ & $0 \%(0)$ & \\
Unchanged or reduced & $21 \%(11)$ & $21 \%(11)$ \\
total & $100 \%(52)$ & \\
\hline
\end{tabular}

Table 5. Multiple linear regression analysis of LSM baseline and LSM change after diet.

\begin{tabular}{lccccc}
\hline & \multicolumn{2}{c}{$\begin{array}{c}\text { Baseline of liver } \\
\text { stiffness }\end{array}$} & & \multicolumn{2}{c}{$\begin{array}{c}\text { Change value of liver } \\
\text { stiffness }\end{array}$} \\
\cline { 2 - 3 } & $\begin{array}{c}\text { Standardized } \\
\text { partial } \\
\text { regression } \\
\text { coefficient B }\end{array}$ & $P$ & & $\begin{array}{c}\text { Standardized } \\
\text { partial } \\
\text { regression } \\
\text { coefficient B }\end{array}$ & $P$ \\
\hline Age & 0.088 & 0.517 & 0.006 & 0.969 \\
BMI & -3.562 & 0.065 & & -1.086 & 0.636 \\
$\begin{array}{l}\text { Baseline of portal } \\
\text { vein blood flow }\end{array}$ & 0.061 & 0.676 & - & - \\
$\begin{array}{l}\text { Changes of portal } \\
\text { venous blood flow }\end{array}$ & - & - & 0.039 & 0.812 \\
$\begin{array}{l}\text { Baseline of liver } \\
\text { stiffness }\end{array}$ & - & - & 0.046 & 0.789 \\
\hline
\end{tabular}

confounding factors, which could affect the measurement, such as exercise, food intake. Therefore, it is very important to determine the factors affecting the accuracy of determination of the liver stiffness. The indication of antiviral therapy in patients with chronic hepatitis mainly depends on the severity of liver fibrosis. If LSM is overestimated, it may lead to unnecessary treatment and unreasonable expenses that countries with limited resources can not afford (Feuth et al., 2013). Moreover, food intake may overestimate the degree of fibrosis in patients and mis-stage them. It has been reported that this condition exists in patients with chronic hepatitis $\mathrm{C}$ virus (HCV) infection (Lemoine et al., 2014). The patients might be excessively divided into pre cirrhosis or cirrhosis after food intake, but LSM was normal on fasting, and no severe fibrosis or cirrhosis was found 
in liver biopsy (Lemoine et al., 2014). Therefore, the main potential confounding factors should be excluded before LSM measurement, or considered when interpreting LSM results.

In this study, we mainly analyzed the effect of food intake on Young's modulus of liver, and analyzed several possible related factors. By using shear wave elastography to measure the average liver stiffness, it was found that the liver stiffness measured at $30 \mathrm{~min}$ or $60 \mathrm{~min}$ after diet was significantly increased compared with the baseline value of Young's modulus. The average LSM was the largest at $60 \mathrm{~min}$, decreased at 60-90 $\mathrm{min}$, and returned to the baseline value at $90 \mathrm{~min}$. after that, the liver stiffness continued to decline slowly, and was decreased compared with the baseline value at $120 \mathrm{~min}$ after diet. Gersak et al. (2016) found that liver stiffness increased significantly 40 minutes after diet, and LSM decreased significantly at 60-80 minutes after diet, while the value of 120 minutes after diet was significantly lower than that of fasting. Though the measurement time points were different compared our study, the change trend of liver stiffness is consistent with our results and dietary has an impact on liver elasticity. This phenomenon not only exists in healthy people, but also in a number of studies on patients with chronic liver disease, it has been found that the liver stiffness after diet has increased significantly, and the increase of LSM in patients with chronic liver disease and liver cirrhosis is more obvious and lasts longer than that of healthy people (Berzigotti et al., 2013; Abenavoli et al., 2017). Mederacke et al. (2009) first reported a significant and long-term increase in LSM in patients with chronic hepatitis $\mathrm{C}$ immediately after diet, and concluded that liver elasticity should be measured after fasting for at least 3 hours.

In this study, we also analyzed the percentage of increase in liver stiffness. After diet LSM increased in 79\% of the volunteers, among them, $31 \%$ of the subjects showed an increase of more than $20 \%$ of the liver stiffness. $21 \%$ of the volunteers had no change or decrease in LSM. Berzigotti et al. (2013) found that postprandial liver stiffness increased significantly by $27 \%$. LSM increased in 15 cases, LSM remained unchanged in 1 case and decreased in 3 cases, which was consistent with our results. LSM assessment by both TE imaging and ARFI imaging were affected by food intake. The LSM began to increase at 15 minutes after diet, and returned to baseline value 2-3 hours after diet (Popescu et al., 2013; Arena et al., 2013; Goertz et al., 2012). In this study, shear wave elastography found that the effect of diet on liver stiffness of healthy people lasted for two hours after diet. It was suggested that LSM should be measured after one night of fasting following the guideline (Dietrich et al., 2017).

Not all the volunteers' liver stiffness increased after diets or at a fixed time point. There were differences among different individuals. Therefore, it is necessary to evaluate the liver stiffness peak value of each volunteer, that is, the maximum liver stiffness value after food intake. This value is more representative of the importance of increasing LSM after a diet, which is clinically representative, rather than the average value at $30 \mathrm{~min}$ or $60 \mathrm{~min}$ after diet.

Petzold et al. (2019a) found that standard liquid diet intake significantly increased LSM in healthy people, with an average increase of $21.6 \%$. In our study, it was found that $31 \%$ of the total population increased LSM by more than $20 \%$, and the intake of standard diet significantly increased the liver stiffness. Compared with the baseline value of liver stiffness under fasting condition, the average peak liver stiffness increased by $12.8 \%$ (male $8.3 \%$, female $15.6 \%$ ). In previous study, the average stiffness value under fasting conditions increased by $2.2 \%$ in the whole sample, $6.1 \%$ in men and $2.3 \%$ in women (Popescu et al., 2013). The difference may be due to that the number of male volunteers is relatively small in our study, and the proportion of men who studied the liver elasticity is basically unchanged or reduced. It may also be due to that we use a standard liquid diet, and the different nature and quantity of food intake can also cause different changes in liver stiffness.

In this study, the liver stiffness of male volunteers at different time points before and after diets was consistent with the value of women, but the average liver stiffness value of men was higher than that of women, which was also in accordance with the results of previous study (Popescu et al., 2013; Mulabecirovic et al., 2018). There was no correlation between the increase value of liver hardness 60 minutes after diet and gender, which was consistent with previous study (Petzold et al., 2019a). It was found that BMI, age had no influence on Young's modulus, which was also confirmed by other studies (Mulabecirovic et al., 2018; Gersak et al., 2016; Silva et al., 2019).

In this study, there was no correlation between the changes of portal vein blood flow and liver stiffness, the baseline value of liver stiffness and the change of liver stiffness, and the baseline value of portal vein blood flow and the baseline value of liver stiffness. Petzold et al. (2019b) has also found that there was no correlation between LSM and portal venous blood flow. It may be due to that the changes of portal blood flow are not synchronous with the changes of liver stiffness. Our study found that portal vein blood flow reached its maximum value at 30 minutes after diet.

Dauzat et al. (1994) measured the blood flow of portal vein after uptake of liquid food and found that the blood flow had increased at 15 minutes and reached the maximum at 30 minutes after diet. In this study, the changes of liver stiffness and portal vein blood flow were the differences between $60 \mathrm{~min}$ after diet and before diet, and the Young's modulus of liver at $60 \mathrm{~min}$ after diet was equal to or even lower than the baseline value, which may be the reason why the increase of liver stiffness has no significant correlation with the increase of portal vein blood flow.

The main limitation of this study was that the instruction of intra- and interobserver reliability tests were not performed. The stiffness measurements only obtained 3 times. In this study, no correlation was found between the baseline value of liver stiffness and the change of liver stiffness, and the baseline value of portal vein blood flow with the baseline value of liver stiffness. However, Petzold et al. (2019a) showed that the baseline value of LSM was negatively correlated with the increase value of LSM after diet, which may be related to the differences of liver mechanical properties and hemodynamics in different individuals.

There were also some limitations of this study. The patients included in this study was overwhelmingly young with mean age of 26 years, thin (BMI of 23) and male patients accounted for about two thirds of the total patients, which might affect 
our result. The minimum fasting time was not evaluated in this study. Further study with more strict design and larger sample size was needed.

In conclusion, diet could affect the Young's modulus measurement of liver. In order to avoid the effect, it is suggested to use real-time shear wave elastic imaging to measure the Young's modulus of liver in fasting state.

\section{References}

Abenavoli, L., Greco, M., Milic, N., Accattato, F., Foti, D., Gulletta, E., \& Luzza, F. (2017). Effect of Mediterranean Diet and Antioxidant Formulation in Non-Alcoholic Fatty Liver Disease: A Randomized Study. Nutrients, 9(8), 870. http://dx.doi.org/10.3390/nu9080870. PMid:28805669.

Arena, U., Lupsor Platon, M., Stasi, C., Moscarella, S., Assarat, A., Bedogni, G., Piazzolla, V., Badea, R., Laffi, G., Marra, F., Mangia, A., \& Pinzani, M. (2013). Liver stiffness is influenced by a standardized diet in patients with chronic hepatitis $\mathrm{C}$ virus at different stages of fibrotic evolution. Hepatology, 58(1), 65-72. http://dx.doi.org/10.1002/ hep.26343. PMid:23447459.

Barr, R. G. (2018). Shear wave liver elastography. Abdominal Radiology, 43(4), 800-807. http://dx.doi.org/10.1007/s00261-017-1375-1. PMid:29116341.

Berzigotti, A., De Gottardi, A., Vukotic, R., Siramolpiwat, S., Abraldes, J. G., García-Pagan, J. C., \& Bosch, J. (2013). Effect of diet ingestion on liver stiffness in patients with cirrhosis and portal hypertension. PLoS One, 8(3), e58742. http://dx.doi.org/10.1371/journal.pone.0058742. PMid:23520531.

Castera, L. (2012). Noninvasive methods to assess liver disease in patients with hepatitis B or C. Gastroenterology, 142(6), 1293-1302. e4. http://dx.doi.org/10.1053/j.gastro.2012.02.017. PMid:22537436.

Darweesh, S. K., Zayed, N., Atef, M., Ramzy, E., Yousry, A., \& Musa, S. (2020). Increased liver stiffness by transient elastography and acoustic radiation force impulse imaging in patients with extrahepatic cholestasis. European Journal of Gastroenterology \& Hepatology. In press. http://dx.doi.org/10.1097/MEG.0000000000001881. PMid:32804844.

Dauzat, M., Lafortune, M., Patriquin, H., \& Pomier-Layrargues, G. (1994). Diet induced changes in hepatic and splanchnic circulation: a noninvasive Doppler study in normal humans. European Journal of Applied Physiology and Occupational Physiology, 68(5), 373-380. http://dx.doi.org/10.1007/BF00843732. PMid:8076615.

Dietrich, C. F., Bamber, J., Berzigotti, A., Bota, S., Cantisani, V., Castera, L., Cosgrove, D., Ferraioli, G., Friedrich-Rust, M., Gilja, O. H., Goertz, R. S., Karlas, T., de Knegt, R., de Ledinghen, V., Piscaglia, F., Procopet, B., Saftoiu, A., Sidhu, P. S., Sporea, I., \& Thiele, M. (2017). EFSUMB guidelines and recommendations on the clinical use of liver ultrasound elastography, update 2017 (long version). Ultraschall in der Medizin, 38(4), e16-e47. http://dx.doi. org/10.1055/s-0043-103952. PMid:28407655.

Feuth, T., Arends, J. E., Lieveld, F. I., Mundt, M. W., Hoepelman, A. I., Siersema, P. D., \& van Erpecum, K. J. (2013). Impact of transient elastography on clinical decision-making in patients with chronic viral hepatitis. Scandinavian Journal of Gastroenterology, 48(9), 1074-1081. http://dx.doi.org/10.3109/00365521.2013.819441. PMid:23886398.

Gersak, M. M., Badea, R., Lenghel, L. M., Vasilescu, D., Botar-Jid, C., \& Dudea, S. M. (2016). Influence of food intake on 2-d shear wave elastography assessment of liver stiffness in healthy subjects.
Ultrasound in Medicine \& Biology, 42(6), 1295-1302. http://dx.doi. org/10.1016/j.ultrasmedbio.2016.01.003. PMid:26947447.

Goertz, R. S., Egger, C., Neurath, M. F., \& Strobel, D. (2012). Impact of food intake, ultrasound transducer, breathing maneuvers and body position on acoustic radiation force impulse (ARFI) elastometry of the liver. Ultraschall in der Medizin, 33(4), 380-385. http://dx.doi. org/10.1055/s-0032-1312816. PMid:22723037.

Kjærgaard, M., Thiele, M., Jansen, C., Stæhr Madsen, B., Görtzen, J., Strassburg, C., Trebicka, J., \& Krag, A. (2017). High risk of misinterpreting liver and spleen stiffness using 2D shear-wave and transient elastography after a moderate or high calorie diet. PLoS One, 12(4), e0173992. http://dx.doi.org/10.1371/journal. pone.0173992. PMid:28376114.

Lemoine, M., Shimakawa, Y., Njie, R., Njai, H. F., Nayagam, S., Khalil, M., Goldin, R., Ingiliz, P., Taal, M., Nyan, O., Corrah, T., D’Alessandro, U., \& Thursz, M. (2014). Food intake increases liver stiffness measurements and hampers reliable values in patients with chronic hepatitis B and healthy controls: the PROLIFICA experience in The Gambia. Alimentary Pharmacology \& Therapeutics, 39(2), 188-196. http://dx.doi.org/10.1111/apt.12561. PMid:24308698.

Mederacke, I., Wursthorn, K., Kirschner, J., Rifai, K., Manns, M. P., Wedemeyer, H., \& Bahr, M. J. (2009). Food intake increases liver stiffness in patients with chronic or resolved hepatitis $C$ virus infection. Liver International, 29(10), 1500-1506. http://dx.doi. org/10.1111/j.1478-3231.2009.02100.x. PMid:19732330.

Mulabecirovic, A., Mjelle, A. B., Gilja, O. H., Vesterhus, M., \& Havre, R. F. (2018). Liver elasticity in healthy individuals by two novel shear-wave elastography systems-Comparison by age, gender, BMI and number of measurements. PLoS One, 13(9), e0203486. http:// dx.doi.org/10.1371/journal.pone.0203486. PMid:30216377.

Petzold, G., Grieme, B., Bremer, S. C. B., Knoop, R. F., Goetze, R. G., Ellenrieder, V., Kunsch, S., \& Neesse, A. (2019a). Prospective comparison of 2D-shearwave elastography in both liver lobes in healthy subjects and in patients with chronic liver disease. Scandinavian Journal of Gastroenterology, 54(9), 1138-1145. http://dx.doi.org/10.1080/003 65521.2019.1653961. PMid:31433262.

Petzold, G., Porsche, M., Ellenrieder, V., Kunsch, S., \& Neesse, A. (2019b). Impact of food intake on liver stiffness determined by 2-D shear wave elastography: prospective interventional study in 100 healthy patients. Ultrasound in Medicine \& Biology, 45(2), 402-410. http:// dx.doi.org/10.1016/j.ultrasmedbio.2018.09.021. PMid:30396598.

Popescu, A., Bota, S., Sporea, I., Sirli, R., Danila, M., Racean, S., Suseanu, D., Gradinaru, O., \& Ivascu Siegfried, C. (2013). The influence of food intake on liver stiffness values assessed by acoustic radiation force impulse elastography-preliminary results. Ultrasound in Medicine \& Biology, 39(4), 579-584. http://dx.doi.org/10.1016/j. ultrasmedbio.2012.11.013. PMid:23415282.

Silva, M., Costa Moreira, P., Peixoto, A., Santos, A. L., Lopes, S., Gonçalves, R., Pereira, P., Cardoso, H., \& Macedo, G. (2019). Effect of diet ingestion on liver stiffness and controlled attenuation parameter. GE Portuguese Journal of Gastroenterology, 26(2), 99-104. http:// dx.doi.org/10.1159/000488505. PMid:30976614.

Xu, N., Xie, Q., Li, J., Gao, Y., \& Li, X. (2020). Improvement in liver stiffness measurement for diagnosis of liver fibrosis in patients with concurrent chronic hepatitis B and nonalcoholic fatty liver disease. The Journal of International Medical Research, 48(2), 300060520903667. http://dx.doi.org/10.1177/0300060520903667. PMid:32070159. 